\title{
Fitness of chassis cells and metabolic pathways for L-cysteine overproduction in Escherichia coli
}

\author{
Han Liu ${ }^{1}$, Yu Wang ${ }^{1}$, Yehua Hou ${ }^{1}$, and Zhimin $\mathrm{Li}^{1}$ \\ ${ }^{1}$ East China University of Science and Technology
}

September 21, 2020

\begin{abstract}
L-cysteine is a ubiquitous and unique sulfur-containing amino acid with important physiological functions. The efficient L-cysteine production via microbial fermentation is interesting and has been paid great attention. In this study, different Escherichia coli K-12 strains (JM109, BW25113, MG1655, W3110) were investigated on their suitability to cysteineproducing plasmid pLH03. The enhancement of precursor synthetic pathway and thiosulfate assimilation pathway resulted in the good performance of BW25113. The expressions of synthetic pathway genes were optimized by two constitutive promoters to assess their effects on L-cysteine production. Main degradation pathway genes were also deleted coordinately for more efficient production of cysteine. The L-cysteine production was further increased through the manipulation of sulfur transcription regulator cysB and sulfur supplement. After the process optimization in a $1.5 \mathrm{~L}$ bioreactor, the fi-

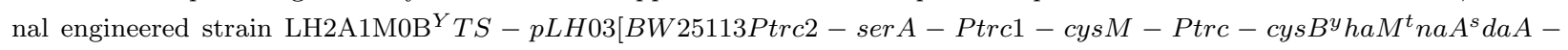
( $p$ LH03)] accumulated8.34g/Lofcysteine, layingacertain foundation forcysteinefermentationindustry.
\end{abstract}

\section{Introduction}

Cys is an important sulfur-containing amino acid for various industries, including cosmetic, pharmaceutical, food and agricultural. Traditionally, the commercial production of Cys has depended on hydrolysis of keratin, which has serious environmental problems (Wendisch, 2020). Recently, an eco-friendly in vitro Cys biosynthesis has appeared, however, this method requires expensive and unstable cofactors (Hanatani et al., 2019). Compared to these methods, microbial fermentation of Cys is a more viable production process because it has the advantages of cost-effectiveness, scalability and eco-friendliness (Nonaka et al., 2017; Joo et al., 2017). Although the amino acid fermentation is a success story of biotechnology, the highly efficient Cys fermentation is still not available, which is a major challenge for amino acid industry (Nakamori, 2017; Shinichi, 2017).

Many microorganisms, including Escherichia coli (Liu et al., 2018; Liu et al., 2020), Corynebacterium glutamicum (Wei et al., 2019; Kondoh et al., 2019) and Pantoea ananatis (Takumi et al., 2017), have been engineered for Cys production. The highest titers of Cys ever reported in C. glutamicum and P. ananatis were about $1.0 \mathrm{~g} / \mathrm{L}$ (Wei et al., 2019) and $2.2 \mathrm{~g} / \mathrm{L}$ (Takumi et al., 2017), respectively. However, $7.5 \mathrm{~g} / \mathrm{L}$ of Cys has been achieved in E. coli (Liu et al., 2020). Over the past 20 years, four E. coli K-12 strains (BW25113, JM109, W3110, MG1655) have been applied in Cys production (Table 1). The genotypes of some key genes in these chassis cells may be slightly different, which affect bacterial metabolism seriously. For example, the genetic differences in crp among E. coli K-12 strains affect sulfur metabolism (Naoyuki et al., 2019). Moreover, it has been demonstrated that transcription levels of key metabolic genes are the major cause for different glucose utilization pathways in E. colistrains (Phue et al., 2004). Therefore, the selection of suitable chassis for Cys production is the basis for better implementing metabolic engineering strategies. 
As shown in Table 1, the metabolic engineering strategies for increasing Cys production include enhancing excretion (ydeD , yfiK, tolC ) and biosynthesis (cysE, serA, serC, serB , cysM, nrdH, glpE ), weakening degradation / transformation (yhaM, tnaA, sdaA, yciW ), and regulating sulfur transcription regulator $($ cys $B)$. These metabolic engineering strategies are often used in combination to significantly increase Cys production (Wendisch, 2020; Takagi et al., 2017). However, these existing works focused on the modification of metabolic pathways, while ignored the fitness of chassis cells and metabolic pathways. Although LH16 achieved high titer $(7.5 \mathrm{~g} / \mathrm{L})$ and sulfur conversion rate $(90.1 \%)$ in fed-batch fermentation, the growth limitation of LH16 could not be well resolved (Liu et al., 2020). Simplifying the expression of metabolic pathways to balance growth and production is the key to efficient production of Cys.

In this study, we described the development of a genetically engineered $E$. coli strain for Cys overproduction. Screening a suitable chassis cell, optimizing the expression combinations of synthetic pathway genes and the deletion combinations of degradation pathway genes, and regulating the expression of sulfur regulator and sulfur supplement were all conducive to establish high-level Cys fermentation. The resulting strain showed the increased growth and production during fed-batch fermentation, resulting in the highest titer reported so far $(8.34 \mathrm{~g} / \mathrm{L})$. All of these modulations are shown in Figure 1.

\section{Materials and methods}

\subsection{Strains and plasmids}

All strains and plasmids constructed in this study are listed in Table 2. The primers for PCR are listed in Table S1. Promoter replacement and gene deletion on the chromosome were performed by using the onestep inactivation method as previously reported (Datsenko, 2000). The inducible trc promoter (Ptrc) was modified by site-directed mutagenesis of 2 bases and 3 bases, yielding constitutive promoters of Ptrc1 and Ptrc2, respectively. The sequences of these promoters are listed in Table S2. One step cloning kit (Vazyme Viotech Co., Ltd.) was used to construct pLH02-1, pLH02-2, and pLH02-3.

\subsection{Medium and cultivation}

LB medium $(10 \mathrm{~g} / \mathrm{L}$ tryptone, $5 \mathrm{~g} / \mathrm{L}$ yeast extract, $10 \mathrm{~g} / \mathrm{L} \mathrm{NaCl})$ was used to propagate the $E$. coli strains. SM1 medium contained $10 \mathrm{~g} / \mathrm{L}$ glucose, $12 \mathrm{~g} / \mathrm{L} \mathrm{K}_{2} \mathrm{HPO}_{4}, 3 \mathrm{~g} / \mathrm{L} \mathrm{KH}_{2} \mathrm{PO}_{4}, 0.1 \mathrm{~g} / \mathrm{L} \mathrm{NaCl}, 5 \mathrm{~g} / \mathrm{L}\left(\mathrm{NH}_{4}\right)_{2} \mathrm{~S}_{2} \mathrm{O}_{3}$, $0.3 \mathrm{~g} / \mathrm{L} \mathrm{MgSO}_{4} \cdot 7 \mathrm{H}_{2} \mathrm{O}, 0.015 \mathrm{~g} / \mathrm{L} \mathrm{CaCl}{ }_{2} \cdot 2 \mathrm{H}_{2} \mathrm{O}, 0.002 \mathrm{~g} / \mathrm{L} \mathrm{FeSO}_{4} \cdot 7 \mathrm{H}_{2} \mathrm{O}, 1 \mathrm{~g} / \mathrm{L}$ trisodium citrate, $5 \mathrm{mg} / \mathrm{L}$ vitamin $\mathrm{B} 1$ and $1 \mathrm{~mL} / \mathrm{L}$ of trace element solution (Liu et al., 2018). If necessary, $50 \mathrm{mg} / \mathrm{L}$ apramycin or $50 \mathrm{mg} / \mathrm{L}$ kanamycin was added. For the promoter-reporter assay, recombinant strains were inoculated into 96-well plates containing $100 \mu \mathrm{L}$ SM1 medium at $30 C$ and 400 rpm for 24 hours.

Batch-fermentation was carried out in $250 \mathrm{ml}$ flasks. The primary and secondary cultures were cultured in LB for 20 and 12 hours, respectively. Subsequently, $1 \mathrm{ml}$ of seed culture was inoculated into $50 \mathrm{~mL}$ of SM1 and incubated at $30 C$ and $220 \mathrm{rpm}$ for 48 hours. For the induction of cys $B$ expression, $0.1 \mathrm{mM}$ isopropyl $\beta$-D-1-thiogalactopyranoside (IPTG) was added when the $\mathrm{OD}_{600}$ reached 0.6-0.8.

Fed-batch culture was performed in a 1.5-L bioreactor (Baoxing Biotech Co., Shanghai, China). The primary culture was cultured in LB for 12 hours. The secondary culture was activated in $50 \mathrm{~mL}$ of SM1 (containing $10 \mathrm{~g} / \mathrm{L}$ tryptone and $5 \mathrm{~g} / \mathrm{L}$ yeast extract). After 8 hours of cultivation, $150 \mathrm{ml}$ seed cultures were combined to inoculate $1 \mathrm{~L}$ of SM1 medium (containing $5 \mathrm{~g} / \mathrm{L}$ glucose, $10 \mathrm{~g} / \mathrm{L}$ tryptone, and $5 \mathrm{~g} / \mathrm{L}$ yeast extract). 500 $\mathrm{g} / \mathrm{L}$ glucose was continuously added into the bioreactor after the initial glucose was completely consumed. For the optimization of induction concentration, $0.1,0.2$ or $0.3 \mathrm{mM}$ IPTG was added when the $\mathrm{OD}_{600}$ value reached approximately 20. For the over-production of Cys, the initial concentration of thiosulfate in the medium was $5 \mathrm{~g} / \mathrm{L}$, and then 2, 4 or $6 \mathrm{~g} / \mathrm{L}$ thiosulfate was added in 19 hours. During the fermentation, the $\mathrm{pH}$ was adjusted with $25 \% \mathrm{NH}_{3} \cdot \mathrm{H}_{2} \mathrm{O}$ to maintain the value of 7.0 . The dissolved oxygen was maintained above $30 \%$ by adjusting agitation speed. The temperature was automatically maintained at $30 \mathrm{C}$.

\subsection{Analytical methods}

Cell growth was monitored by measuring $\mathrm{OD}_{600}$, which converted to biomass $\left(\mathrm{DCW}=0.339 \times \mathrm{OD}_{600}\right)(\mathrm{Liu}$ 
et al., 2018), using a UV-7504 Spectrophotometer (Xinmao Instrument, Shanghai, China). Fluorescence intensity was monitored by microplate reader (BioTek Instruments, Winooski, VT, USA). Cys was analyzed with precolumn derivatization by HPLC (LC-10AT, Shimadzu, Japan) using a WondalSil C18 column (GL Sciences Inc., Japan) as described in our previous work (Liu et al., 2018; Liu et al., 2020). The sulfur conversion rate was defined as the percentage of moles of sulfur atoms of the final amount of Cys compared with moles of total sulfur atoms in the medium.

\subsection{Quantitative Real-Time PCR (qRT-PCR)}

The primers for qRT-PCR analysis are listed in Table S1. For transcriptional analysis, cells were harvested from shake flask fermentation in the middle of the exponential phase. RNA extraction and RT-PCR assay were performed as previously described (Huang et al., 2018) .

\section{Results and Discussion}

\subsection{Screening chassis cells for L-cysteine production}

One of the bottlenecks in synthetic biology is the unpredictable cell physiology interference when artificial synthetic elements are transferred into the chassis cells (Choi et al., 2019). Therefore, the suitability of synthetic elements and chassis cells determines the success of newly constructed cell factory. E. coli K-12 derivatives were widely used as the main chassis cells for cysteine production (Table 1). To obtain a more suitable chassis cell, cysteine-producing plasmid pLH03 was transformed into four E. coli K-12 hosts, which resulted in W3110-pLH03, MG1655-pLH03, JM109-pLH03, and BW25113-pLH03. The DCW of BW25113pLH03 reached 1.56+-0.02 g/L, while the DCW of JM109-pLH03, MG1655-pLH03, and W3110-pLH03 had no significant difference (about $1.10 \mathrm{~g} / \mathrm{L}$ ) (Figure 2A). BW25113-pLH03 generated 345.74+-39.01 mg/L Cys, JM109-pLH03 resulted in the production of 190.31+-13.23 mg/L Cys, W3110-pLH03 and MG1655-pLH03 only produced little Cys (less than $70 \mathrm{mg} / \mathrm{L}$ ) (Figure 2A). These results showed that the best chassis for pLH03 was BW25113, followed by JM109, neither W3110 nor MG1655 was suitable for pLH03.

Among various microbial host strains, E. coli has the advantages of mature genome editing tools, numerous metabolic engineering and synthetic biology strategies (Yang et al., 2020). Accordingly, E. coli has been employed as a workhorse for Cys overproduction in fermentation. As early as 1997, the complete genome sequence of $E$. coli K-12 has been presented (Blattner et al., 1997). Recently, it has been demonstrated that genetic differences in crp among $E$. coli $\mathrm{K}-12$ strains affect $\mathrm{H}_{2} \mathrm{~S}$ generation during thiosulfate assimilation (Naoyuki et al., 2019). In addition, carbon regulator crp and sulfur regulator cysB regulated each other (Liu et al., 2020). To elucidate the reasons for the differences in suitability between E. coli K-12 strains and pLH03, two better performing strains (BW25113-pLH03 and JM109-pLH03) were selected for further research. The transcriptional analysis of $\operatorname{crp}, c y s B$ and major synthetic genes was performed. As shown in Figure 2B, compared to the transcription levels of crp and cysBin JM109-pLH03, their transcription levels in BW25113-pLH03 increased by 8.2 times and 6.6 times, respectively. The transcription levels of major sulfur metabolic operons were as follows, cys $M$ increased by 3.8 times, $n r d H$ was almost unchanged (1.3 times), and thecysPUWA increased by 10-22 times (Figure 2B). Similarly, the transcription levels of major carbon metabolic operons were showed as follows, ser $A$ increased by 6.6 times, $\operatorname{ser} C$ increased by 2.8 times, $\operatorname{ser} B$ was almost unchanged (1.2 times). These results indicated that genetic differences in $\mathrm{crp}$ among E. $\operatorname{coliK}$ K-12 strains also affected Cys generation during sulfur assimilation. Specifically, the enhancement of precursor synthetic pathway and thiosulfate assimilative pathway resulted in the better performance of BW25113-pLH03. Therefore, BW25113 was a more promising chassis for implementing metabolic engineering strategies to produce Cys efficiently.

\subsection{Optimization of expression of synthetic pathway genes by two constitutive promoters}

In our previous study, the constitutive promoter $P \operatorname{trc} 1$ was used to overexpress the synthetic pathway genes at the chromosomal level, which significantly improved L-cysteine production (Liu et al., 2020). However, single promoter might not be optimal to obtain maximum metabolic flux towards desired product, by contrast, modulating gene expression with multiple promoters is an option to obtain optimal expression strength 
(Chen et al., 2020). Therefore, each Cys synthesis pathway gene was individually overexpressed by Ptrc1 and $\mathrm{Ptrc} 2$, which is a stronger constitutive promoter than Ptrc1. The relative strength of $\mathrm{Ptrc} 1$ and $\mathrm{Ptrc} 2$ was shown in Figure 3A. The native promoters of ser A, serC , serB, cysM , nrdH , glpE , cysK in BW25113 were replaced with Ptrc1 and Ptrc2 in turn at the chromosome level, yielding LH1A, LH2A, LH1C, LH2C, LH1B, LH2B, LH1M, LH2M, LH1H, LH2H, LH1K, LH2K, LH1E, LH2E, respectively (Figure 3B). Plasmid pLH03 was transformed into these engineered strains for batch fermentation. Overall, overexpression of most synthetic genes by Ptrc1 and Ptrc2 had a positive effect on Cys production (Figure 3C). The overexpression of $c y s K$ and $g l p E$ at any strength failed to increase the production. For cys $M$, the Cys production decreased as promoter strength increased. The sulfur assimilation pathway mediated by $c y s K$ and $g l p E$ demanding high energy and reducing power was not favorable to improve Cys production (Liu et al., 2020). In addition, cys $M$ is not only a Cys synthetase but also a cysteine degrading enzyme (Awano et al., 2005; Awano et al., 2003). The excessive overexpression of cys $M$ by Ptrc2 was not beneficial to enhance Cys production.

In order to introduce more metabolic fluxes into Cys, the synthetic pathway genes with significant differences $\left({ }^{*} \mathrm{p}<0.05\right)$ and higher production (Figure $\left.3 \mathrm{C}\right)$ were combinatorially expressed. Therefore, the engineered strain LH2AC1BMH-pLH03 was constructed. As shown in Figure 3D, the production of Cys of LH2AC1BMH-pLH03 was increased by $20 \%$ compared to that of BW25113-pLH03. However, the DCW of LH2AC1BMH-pLH03 was significantly reduced by $40 \%$ to a value of $0.99 \mathrm{~g} / \mathrm{L}$ compared to that of BW25113pLH03 (Figure 3D). The combined over-expression of multiple genes triggered cell growth burden and imbalance in pathway fluxes, which is a major challenge when attempting to improve metabolic pathway performance (Pfleger et al., 2015). The issue becomes more complex with the increase in the number of genes involved (Nowroozi et al., 2014; Smanski et al., 2014).

To solve this issue, the genes with extremely significant differences $\left({ }^{*} \mathrm{p}<0.01\right)$ and higher production (Figure 3C) were co-overexpressed. Accordingly, we obtained the engineered strain LH2A1M-pLH03. Fortunately, the production of LH2A1M-pLH03 was remarkably improved to $1026+-74.64 \mathrm{mg} / \mathrm{L}$, and a $200 \%$ increase was observed compared with that of BW25113-pLH03 (Figure 3D). More importantly, the DCW of LH2A1MpLH03 only decreased slightly (Figure 3D). From these results, it was concluded that the regulation of bottleneck genes $\left({ }^{*} \mathrm{p}<0.01\right)$ by multiple regulatory elements was a more effective way to balance the pathway fluxes and cell growth. The synthetic physiology showed that slow cell growth due to metabolic burden had many adverse effects on the use of artificial genetic elements (Ji et al., 2017). It is advantageous in terms of stability and metabolic burden to modulate expression of relevant genes on the chromosome rather than relying on overexpression of genes on high-copy vectors (Yuan et al., 2006). Promoter engineering was a powerful tool for rationally tuning the metabolic fluxes and reducing metabolic burden for overproduction of many important bio-based chemicals (Zhao et al., 2019; Chen et al., 2015).

\subsection{Investigation on the multi-deletion of degradation pathway genes}

It is well known that the disruption of degradation pathway for desired amino acid is effective approach to improve amino acid production (Wendisch, 2020; Mundhada et al., 2016). Currently, six Cys degradation genes (tnaA , metC , malY, cysK , cysM ,yhaM ) (Nonaka et al., 2017; Awano et al., 2005) have been identified. However, some Cys degradation genes are also involved in the synthesis of methionine $($ met $C$ and malY ) and Cys (cysK and cys $M$ ). In addition, since the main Ser deaminase among the four Ser degradation genes ( $s d a A, s d a B, t d c G, t d c B$ ) was identified so far (Su et al., 1989; Zhang et al., 2008), SdaA was often deleted alone to improve Ser formation (Wang et al., 2020; Y. Zhang et al., 2018; Gu et al., 2014). To accumulate more Cys, the effect of deletion of yhaM , tnaA, and sdaA in LH2A1M was investigated. Therefore, LH2A1M $\Delta \mathrm{Y}(\Delta y h a M)$-pLH03, LH2A1M $\Delta \mathrm{T}(\Delta$ tnaA )-pLH03, and LH2A1M $\Delta \mathrm{S}(\Delta s d a A)$ pLH03 were constructed. After 48 hours of shake flask fermentation, LH2A1M $\Delta$ Y-pLH03, LH2A1M $\Delta$ TpLH03, and LH2A1M $\Delta$ S-pLH03 resulted in $1271.12 \pm 23.63 \mathrm{mg} / \mathrm{L}, 1329.43 \pm 39.53 \mathrm{mg} / \mathrm{L}$, and $1215.23 \pm 88.32$ $\mathrm{mg} / \mathrm{L}$ of Cys, respectively (Figure 4A). The DCW of these mutant strains was similar to that of LH2A1MpLH03. These results indicated that the effect of single deletion of degradation genes in LH2A1M was significant $\left({ }^{*} \mathrm{p}<0.05\right)$. Naturally, it was reasoned that the effect of combinatorial deletion of degradation genes in LH2A1M would be extremely significant. Accordingly, a triple mutant strain LH2A1M $\Delta$ YTS $(\Delta y h a M$ 
$\Delta$ tnaA $\Delta s d a A$ )-pLH03 was constructed for more efficient production of Cys. As shown in Figure 4A, LH2A1M $\Delta$ YTS-pLH03 resulted in $1514.57 \pm 91.66 \mathrm{mg} / \mathrm{L}$ of Cys (Figure 4A). Similarly, the triple deletions of degradation genes did not affect the cell growth (Figure 4A). These results illustrated that the combinatorial deletion ofyhaM , tnaA, and sdaA was indeed extremely important $(* * \mathrm{p}<0.01)$ for Cys production, which increased the production by approximately $48 \%$ versus that of LH2A1M-pLH03.

To further understand the difference of LH2A1M-pLH03 and LH2A1M $\Delta$ YTS-pLH03, fed-batch fermentations were carried out in a $1.5 \mathrm{~L}$ bioreactor. As shown in Figure 4B, within the first 19 hours, the DCW of LH2A1M $\triangle$ YTS-pLH03 was similar with that of LH2A1M-pLH03. After 19 hours, the DCW of LH2A1M $\triangle$ YTS-pLH03 was higher than that of LH2A1M-pLH03 (Figure 4B). The production of Cys of LH2A1M-pLH03 began to decline rapidly after reaching a maximum of $1.97 \mathrm{~g} / \mathrm{L}$ in 19 hours. In contrast, LH2A1M $\Delta$ YTS-pLH03 could produce Cys continuously. After 24 hours of cultivation, the titer of Cys reached $6.51 \mathrm{~g} / \mathrm{L}$ Cys (Figure $4 \mathrm{C}$ ), which was approximately fivefold higher than that obtained from the flask culture. However, after 24 hours, the production of Cys of LH2A1M $\Delta$ YTS-pLH03 decreased (Figure $4 \mathrm{C})$. These results further demonstrated that the multi-deletion of degradation pathway genes was essential to overproduce Cys, especially at the level of fed-batch fermentation.

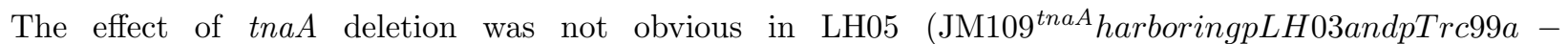
serACB)(Liuetal., 2018).However, itwassignificantin $B W 2 A 1 M^{T}-p L H 03$, whichwasalsoconsistentwithotherstudies (Awo serACB, 49065.0mg/L)(Liuetal., 2018).Incontrast, LH2A1M-pLH03reachedupto1026.3974.64mg/L(Figure 3C).Asshowni batchlevel.AlthoughyhaMandtnaAweredeletedin LH2A1M0BDYTS-pLH03, otherknowndegradationproteins (suchasMet A, OASS-B)orunknowndegradationproteinscouldparticipateinCysdegradation(Nonakaetal., 2017; Awanoetal., 2005).The

\subsection{Simultaneous manipulation of sulfur regulator $c y s B$ and sulfur supplement}

The expression of genes for sulfur uptake and reduction (such ascysP, cys $U$, cys $W$, cys $A$, cys $M$, cysK ) is under the control of the transcriptional activator CysB. Overexpression of these genes did not necessarily improve the Cys production (Figure $3 \mathrm{C}$, cysK ). It is still challenging to manipulate metabolic pathways consisting of large number of genes (Zhang et al., 2008). Therefore, it was reasonable to regulate the expression of these genes by controlling the expression of $c y s B$. To reduce the risk of extra metabolic burdens caused by high-copy plasmid, the native promoter of $c y s B$ in LH2A1M $\Delta$ YTS was replaced with inducible promoter Ptrc, yielding the LH2A1M0B $\Delta$ YTS. The effect of cysBregulation by Ptrc on Cys production was firstly verified in flasks. As shown in Figure 5A, the DCW of LH2A1M $\Delta$ YTS-pLH03 and LH2A1M0B $\Delta$ YTS-pLH03 exhibited little difference. LH2A1M0B $\Delta$ YTS-pLH03 accumulated $1723.93 \pm 31.44 \mathrm{mg} / \mathrm{L}$ of Cys (Figure 5A), an $16 \%$ increase versus that of LH2A1M $\Delta$ YTS-pLH03. These results showed that the inducible expression of cysB by Ptrc at the chromosome level was effective for improving Cys production.

To further explore the potential of the LH2A1M0B $\Delta$ YTS-pLH03, fed-batch culture was also carried out in a $1.5 \mathrm{~L}$ bioreactor. Previously, LH2A1M $\Delta$ YTS-pLH03 produced $6.51 \mathrm{~g} / \mathrm{L}$ of Cys with a sulfur conversion rate of $80 \%$, which suggested that the initial $5 \mathrm{~g} / \mathrm{L}$ thiosulfate in the medium could not meet the requirements for further over-production of Cys. Excessive initial thiosulfate will affect cells growth and physiological functions (Kawano et al., 2018; Yamazaki et al., 2020). Therefore, a sulfur supplement strategy was adopted during the fed-batch culture. Additionally, to optimize the expression of $c y s B$ to improve sulfur utilization, different induction doses of IPTG were also compared accompanying with the sulfur supplement strategy.

First, the effects of different concentrations of IPTG $\left(0.1^{\sim} 0.3 \mathrm{mM}\right)$ with $2 \mathrm{~g} / \mathrm{L}$ thiosulfate supplement were investigated. The DCW of LH2A1M0B $\Delta$ YTS-pLH03 under these conditions were almost the same (Figure $5 \mathrm{~B}$ ). The production of Cys increased when the inducer concentration raised from $0.1 \mathrm{mM}$ to $0.2 \mathrm{mM}$ (Figure $5 \mathrm{C})$. However, the production of Cys did not improve when the inducer concentration raised from $0.2 \mathrm{mM}$ to $0.3 \mathrm{mM}$ (Figure 5C). Approximately $7.25 \mathrm{~g} / \mathrm{L}$ of Cys was detected with the addition of $0.2 \mathrm{mM}$ of IPTG and $2 \mathrm{~g} / \mathrm{L}$ thiosulfate. These results preliminarily illustrated that the simultaneous manipulation of sulfur regulator cysB and sulfur addition strategy was useful for over-production of Cys.

Then, the effects of different concentrations of additional thiosulfate $(2 \sim 6 \quad \mathrm{~g} / \mathrm{L})$ with 0.2 $\mathrm{mM}$ IPTG were examined. As shown in Figure 5D, the cell growth of LH2A1M0B $\Delta$ YTS- 
pLH03 was also not affected under these conditions. The DCW of LH2A1M0B ${ }^{Y}$ TS pLH03reachedupto $12.6 \mathrm{~g} / \mathrm{L}$, approximately50\% increaseversusthatof LH16(Liuetal., 2020).TheproductionofCysimprovedu pLH03accumulated8.34g/LofCysundertheconditionof supplementwith0.2mMof IPTGand $4 \mathrm{~g} /$ Lthiosulfate(Figure 5 E).Th productionofCys.

Cys production differed in the presence of different concentrations of IPTG, indicating that the expression of cysB significantly affected Cys production. As sulfur regulator cysB could regulate all sulfur assimilation pathways to improve Cys production (Liu et al., 2020), the sulfur supplement strategy would be more effective under the proper expression of CysB (such as $0.2 \mathrm{mM}$ IPTG). However, thiosulfate also acted as anti-inducer for CysB (Takagi et al., 2017), thus affecting the production of Cys (such as $6 \mathrm{~g} / \mathrm{L}$ thiosulfate). Hence, the appropriate concentration of thiosulfate (such as $4 \mathrm{~g} / \mathrm{L}$ thiosulfate) was also very important. In fact, $4 \mathrm{~g} / \mathrm{L}$ thiosulfate was also added in the fed-batch fermentation of LH2A1M ${ }^{Y} T S-p L H 03$. However, itdidnotimprovetheproductionofCysof LH2A1MDYTS pLH03(FigureS2), whichprovedagainthatthecoordinatemanipulationof cysBexpressionandsul fur supplementcouldachieve

\section{Conclusions}

In this study, the suitability of four commonly used E. coli K-12 strains and pLH03 was firstly compared. Based on the optimal chassis cells, the expression in synthetic pathways and the deletion of degradation pathways were optimized. Finally, $8.34 \mathrm{~g} / \mathrm{L}$ Cys was achieved by simultaneous manipulation of sulfur regulator cysB and sulfur supplement strategy. The DCW and Cys production of different metabolically engineered Escherichia coli strains were shown in Table 3 . The described fermentation-based process by LH2A1M0B ${ }^{Y} T S-$ pLH03providesanimportantsteptowardsindustrialproductionof Cysdirectly fromglucose.

\section{Abbreviations Used}

Cys: L-cysteine; IPTG : Isopropyl $\beta$-D-1-thiogalactopyranoside; DCW: Dry cell weight;qRT-PCR: Quantitative real-time polymerase chain reaction; $\mathbf{H}_{2} \mathbf{S}$ : Hydrogen sulfide; Ser: L-serine.

\section{Acknowledgements}

This study was supported by the China National Key Research and Development Program (Grant No. 2019YFA0904300) and the Fundamental Research Funds for the Central Universities (22221818014).

\section{Notes}

The authors declare that they have no competing interests.

\section{References}

Wendisch, V. F. (2020). Metabolic engineering advances and prospects for amino acid production. Metabolic Engineering, 58 , 17-34.

Hanatani, Y., Imura, M., Taniguchi, H., Okano, K., Toya, Y., Iwakiri, R., \& Honda, K. (2019). In vitro production of cysteine from glucose.Applied Microbiology and Biotechnology, 103 (19), 8009-8019.

Nonaka, G., \& Takumi, K. (2017). Cysteine degradation gene yhaM , encoding cysteine desulfidase, serves as a genetic engineering target to improve cysteine production in Escherichia coli . AMB Express, 7 (1), 90.

Joo, Y.-C., Hyeon, J. E., \& Han, S. O. (2017). Metabolic design ofCorynebacterium glutamicum for production of L-cysteine with consideration of sulfur-supplemented animal feed. Journal of Agricultural and Food Chemistry, 65 (23), 4698-4707.

Nakamori, S. (2017). Early history of the breeding of amino acid-producing strains. Advances in Biochemical Engineering/Biotechnology, 159 , 25-53.

Shinichi, H. (2017). Discovery and history of amino acid fermentation.Advances in Biochemical Engineering/Biotechnology, 159 , 15-34. 
Liu, H., Fang, G., Wu, H., Li, Z., \& Ye, Q. (2018). L-Cysteine production in Escherichia coli based on rational metabolic engineering and modular strategy. Biotechnology Journal, No. e1700695.

Liu, H., Hou, Y., Wang, Y., \& Li, Z. (2020). Enhancement of sulfur conversion rate in the production of L-cysteine by engineeredEscherichia coli . Journal of Agricultural and Food Chemistry, 68 (1), 250-257.

Wei, L., Wang, H., Xu, N., Zhou, W., Ju, J., Liu, J., \& Ma, Y. (2019). Metabolic engineering of Corynebacterium glutamicum for L-cysteine production. Applied Microbiology and Biotechnology, 103 , 1325-1338.

Kondoh, M., \& Hirasawa, T. (2019). L-Cysteine production by metabolically engineered Corynebacterium glutamicum .Applied Microbiology and Biotechnology, 103 , 2609-2619.

Takumi, K., Ziyatdinov, M. K., Samsonov, V., Nonaka, G., \& Vieille, C. (2017). Fermentative production of cysteine by Pantoea ananatis .Applied and Environmental Microbiology, 83 (5), e02502-02516.

Naoyuki, T., Tomoyuki, H., Soshi, S., Yukari, W., Tetsuya, A., Yusuke, K., \& Iwao, O. (2019). Generation of hydrogen sulfide from sulfur assimilation in Escherichia coli . Journal of General and Applied Microbiology., 65 (5), 234-239.

Phue, J., \& Shiloach, J. (2004). Transcription levels of key metabolic genes are the cause for different glucose utilization pathways inE. coli B (BL21) and E. coli K (JM109). Journal of Biotechnology, 109 (109), 21-30.

Takagi, H., \& Ohtsu, I. (2017). L-Cysteine metabolism and fermentation in microorganisms. Advances in Biochemical Engineering/Biotechnology, 159 , 129-151.

Datsenko, K. A. W., B.L. (2000). One-step inactivation of chromosomal genes in Escherichia coli K-12 using PCR products. Proceedings of the National Academy of Sciences of the United States of Americ, 97 (12), 6640-6645.

Huang, B., Yang, H., Fang, G., Zhang, X., Wu, H., Li, Z., \& Ye, Q. (2018). Central pathway engineering for enhanced succinate biosynthesis from acetate in Escherichia coli . Biotechnology and Bioengineering, 115 (4), 943-954.

Choi, K. R., Jang, W. D., Yang, D., Cho, J. S., Park, D., \& Lee, S. Y. (2019). Systems metabolic engineering strategies: Integrating systems and synthetic biology with metabolic engineering. Trends in Biotechnology, 37 (8), 817-837.

Yang, D., Park, S. Y., Park, Y. S., Eun, H., \& Lee, S. Y. (2020). Metabolic engineering of Escherichia coli for natural product biosynthesis. Trends in Biotechnology, 38 (7), 745-765.

Blattner, F. R., Plunkett, G. 3rd., Bloch, C. A., Perna, N. T., Burland, V., Riley, M., . . . Shao, Y. (1997). The complete genome sequence ofEscherichia coli K-12. Science, 277 (5331), 1453.

Chen, X., Dong, X., Liu, J., Luo, Q., \& Liu, L. (2020). Pathway engineering of Escherichia coli for $\alpha$ etoglutaric acid production. Biotechnology and Bioengineering, 117 , 2791-2801.

Awano, N., Wada, M., Mori, H., Nakamori, S., \& Takagi, H. (2005). Identification and functional analysis of Escherichia colicysteine desulfhydrases. Applied and Environmental Microbiology, 71 (7), 4149-4152.

Awano, N., Wada, M., Kohdoh, A., Oikawa, T., Takagi, H., \& Nakamori, S. (2003). Effect of cysteine desulfhydrase gene disruption on L-cysteine overproduction in Escherichia coli. Applied Microbiology and Biotechnology, 62 (2-3), 239-243.

Pfleger, B. F., \& Prather, K. L. J. (2015). Biological synthesis unbounded? Nature Biotechnology, 33 (11), 1148-1149.

Nowroozi, F. F., Baidoo, E. E. K., Ermakov, S., Redding-Johanson, A. M., Batth, T. S., Petzold, C. J., \& Keasling, J. D. (2014). Metabolic pathway optimization using ribosome binding site variants and combinatorial gene assembly. Applied Microbiology and Biotechnology, 98 (4), 1567-1581. 
Smanski, M. J., Bhatia, S., Zhao, D., Park, Y., Woodruff, L. B. A., Giannoukos, G., . . . Voigt, C. A. (2014). Functional optimization of gene clusters by combinatorial design and assembly. Nature Biotechnology, 32 (12), 1241-1249.

Ji, X., Zhao, H., \& Lou, C. (2017). Advances in synthetic physiology of artificial genetic parts. Chinese Journal of Biotechnology, 33 , 393-403.

Yuan, L. Z., Rouvière, P. E., Larossa, R. A., \& Suh, W. (2006). Chromosomal promoter replacement of the isoprenoid pathway for enhancing carotenoid production in E. coli . Metabolic Engineering, 8 (1), 79-90.

Zhao, F., Liu, X., Kong, A., Zhao, Y., Fan, X., Ma, T., . . . Yang, C. (2019). Screening of endogenous strong promoters for enhanced production of medium-chain-length polyhydroxyalkanoates in Pseudomonas mendocina NK-01. Scientific Reports, 9 (1), 1798.

Chen, X., Zhu, P., \& Liu, L. (2015). Modular optimization of multi-gene pathways for fumarate production. Metabolic Engineering, 33, 76-85.

Mundhada, H., Schneider, K., Christensen, H. B., \& Nielsen, A. T. (2016). Engineering of high yield production of L-serine inEscherichia coli . Biotechnology and Bioengineering, 113 (4), 807-816.

Su, HS., Lang, BF., \& Newman, EB. (1989). L-serine degradation inEscherichia coli K-12: cloning and sequencing of the sdaAgene. Journal of Bacteriology, 171 (9), 5095-5102.

Zhang, X, \& Newman, E. (2008). Deficiency in L-serine deaminase results in abnormal growth and cell division of Escherichia coli K-12.Molecular Microbiology, 69 (4), 870-881.

Wang, C., Wu, J., Shi, B., Shi, J., \& Zhao, Z. (2020). Improving L-serine formation by Escherichia coli by reduced uptake of produced L-serine. Microbial Cell Factories, 19 (1), 66.

Zhang, Y., Shang, X., Lai, S., Zhang, Y., Hu, Q., Chai, X., . . . Wen, T. (2018). Reprogramming one-carbon metabolic pathways to decouple L-Serine catabolism from cell growth in Corynebacterium glutamicum . Acs Synthetic Biology, 7 (2), 635.

Gu, P., Yang, F., Su, T., Li, F., Li, Y., \& Qi, Q. (2014). Construction of an L-serine producing Escherichia coli via metabolic engineering. Journal of Industrial Microbiology and Biotechnology, 41 (9), 1443-1450.

Kawano, Y., Suzuki, K., \& Ohtsu, I. (2018). Current understanding of sulfur assimilation metabolism to biosynthesize L-cysteine and recent progress of its fermentative overproduction in microorganisms. Applied Microbiology and Biotechnology, 102 (19), 8203-8211.

Yamazaki, S., Ziyatdinov, M. K., \& Nonaka, G. (2020). Fermentative production of sulfur-containing amino acid with engineering putative L-cystathionine and L-cysteine uptake systems in Escherichia coli . Journal of Bioscience and Bioengineering, 130 (1), 14-19.

Dassler, T., Maier, T., Winterhalter, C., \& Bock, A. (2000). Identification of a major facilitator protein from Escherichia coli involved in efflux of metabolites of the cysteine pathway.Molecular Microbiology, 36 (5), 1101-1112.

Isabel, F., Armin, R., Tobias, D., Thomas, M., \& August, B. (2003). YfiK from Escherichia coli promotes export of O-Acetylserine and cysteine. Journal of Bacteriology, 185 (4), 1161-1166.

Wiriyathanawudhiwong, N., Ohtsu, I., Li, Z.-D., Mori, H., \& Takagi, H. (2009). The outer membrane TolC is involved in cysteine tolerance and overproduction in Escherichia coli. Applied Microbiology and Biotechnology 81 (5), 903-913.

Nakatani, T., Ohtsu, I., Nonaka, G., Wiriyathanawudhiwong, N., Morigasaki, S., \& Takagi, H. (2012). Enhancement of thioredoxin/glutaredoxin-mediated L-cysteine synthesis from S-sulfocysteine increases Lcysteine production in Escherichia coli . Microbial Cell Factories, 11 (1), 62. 
Kawano, Y., Ohtsu, I., Takumi, K., Tamakoshi, A., Nonaka, G., Funahashi, E., . . . Takagi, H. (2015). Enhancement of L-cysteine production by disruption of yciW in Escherichia coli . Journal of Bioscience and Bioengineering, 119 (2), 176-179.

Kawano, Y., Onishi, F., Shiroyama, M., Miura, M., Tanaka, N., Oshiro, S., . . . Ohtsu, I. (2017). Improved fermentative L-cysteine overproduction by enhancing a newly identified thiosulfate assimilation pathway in Escherichia coli . Applied Microbiology and Biotechnology, 101, 6879-6889.

\section{Figure captions:}

Figure 1. Metabolic engineering strategies for $\boldsymbol{E}$. coli to improve L-cysteine production. Gray boxes and blue arrows represent the genes that were modulated with different constitutive/inducible promoters in the genome. Orange boxes and purple arrows indicate the genes are modulated in the plasmid. Red boxes and arrows show that the genes are knocked out. Genes and enzymes: serA, phosphoglycerate dehydrogenase; $\operatorname{ser} C$, phosphoserine aminotransferase; serB , phosphoserine phosphatase; cysE , serine acetyltransferase; $c y s M$, cysteine synthase $\mathrm{B} ; n r d H$, glutaredoxin-like protein; cys $K$, cysteine synthase A; $g l p E$, thiosulfate sulfurtransferase; $c y s B$, sulfur transcriptional regulator;sdaA, L-serine deaminase; tnaA , L-cysteine desulfhydrase;yhaM, L-cysteine desulfidase; ydeD , L-cysteine exporter;cysPUWA, thiosulfate transporter.

Figure 2. The effect of different $\boldsymbol{E}$. coli K-12 strains as Cys producers. (A) The effect of different E. coli K-12 strains (MG1655, W3110, JM109, BW25113) with pLH03 on DCW and Cys production. (B) Relative transcription levels of cysB, crp ,cysP , cys, , cys $W$, cys $A, c y s M, n r d H, \operatorname{ser} A, \operatorname{ser} C, \operatorname{ser} B$ in BW25113-pLH03 and JM109-pLH03.

Figure 3. The effect of modulating synthesis pathway genes by Ptrc1 and Ptrc2. (A) The relative strength of the constitutive promoter Ptrc1 and Ptrc2. BW25113-pLH02-1 (PcysE -mCherry) was used as the control group, BW25113-pLH02-2 (Ptrc1-mCherry) and BW25113-pLH02-3 (Ptrc2-mCherry) were used as the experimental group. Recombinant strains were inoculated into 96-well plates containing $100 \mu \mathrm{L}$ SM1 medium at 30 and $400 \mathrm{rpm}$ for 24 hours and monitored by microplate reader. (B) A series of synthesis pathway genes ( $\operatorname{ser} A, \operatorname{ser} C, \operatorname{ser} B, \operatorname{cys} M, n r d H, g l p E, \operatorname{cys} K)$ expression cassettes were designed at different expression level. (C) The DCW and Cys production after modulating synthesis pathway genes by Ptrc1 and Ptrc2 individually. Statistically significant differences between the engineered strains and the original strain BW25113-pLH03: ${ }^{*} \mathrm{p}<0.05,{ }^{* *} \mathrm{p}<0.01$. (D) The DCW and Cys production after modulating synthesis pathway genes combinatorially.

Figure 4.The effect of deleting degradation pathway genes in different levels. (A) The DCW and Cys production after deleting degradation pathway genes (yhaM, tnaA, sdaA ) individually and combinatorially in the batch fermentation. Statistically significant differences between the engineered strains and the original strain LH2A1M-pLH03: ${ }^{*} \mathrm{p}<0.05,{ }^{*} \mathrm{p}<0.01$. (B) The DCW of LH2A1M-pLH03 and LH2A1M ${ }^{Y} T S-p L H 03 i n f e d-$ batch fermentation. (C)TheL-cysteineofLH2A1MpLH03andLH $2 A 1 M^{Y} T S-p L H 03$ infed - batchfermentation.

Figure 5. The effect of simultaneous manipulation of sulfur regulator cysB and sulfur addition strategy. (A) The DCW and Cys production of LH2A1M0B ${ }^{Y} T S$ pLH03inbatch fermentation.Fortheinductionof cysBexpression, 0.1 mMIPTGwasaddedwhentheOD $D_{600}$ reached0.60.8.(B)T

\section{Tables}

Table 1 L-Cysteine production of different metabolically engineered $E$. coli strains 


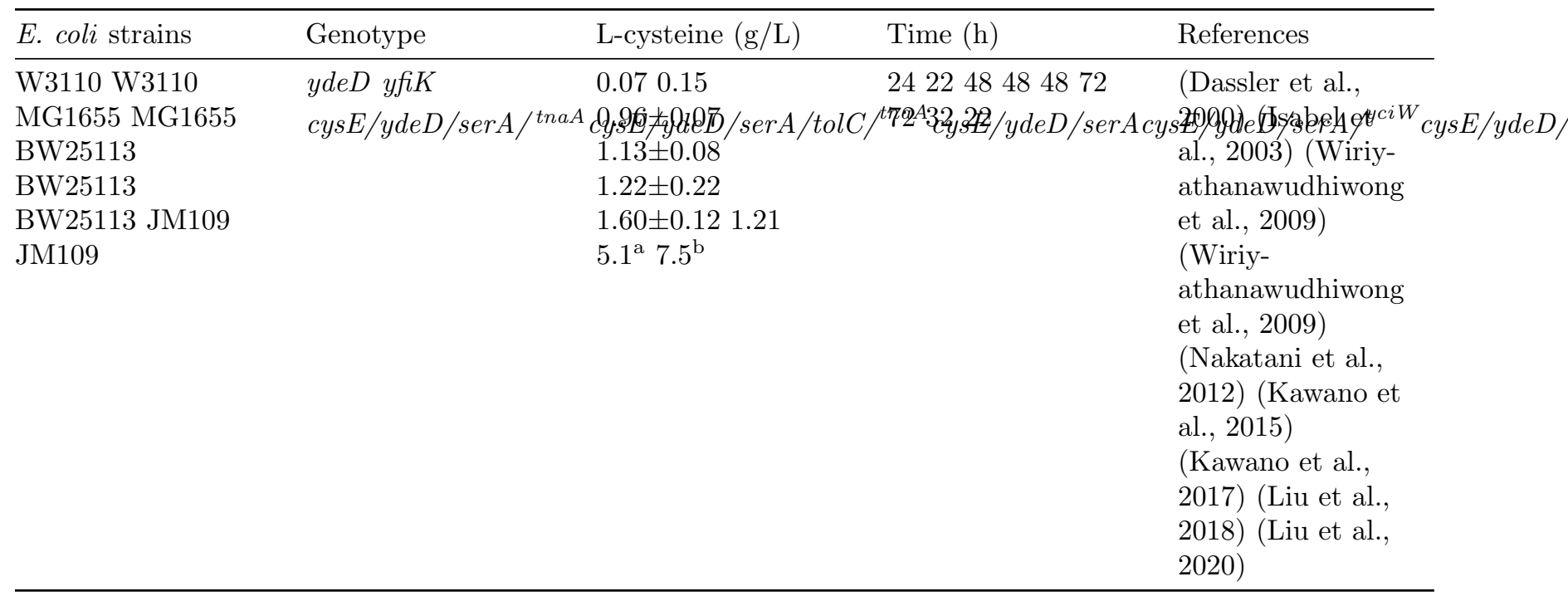

a Fed-batch fermentation was performed in a $5 \mathrm{~L}$ bioreactor.

b Fed-batch fermentation was performed in a $1.5 \mathrm{~L}$ bioreactor.

Table 2 Strains and plasmids used in this study

Name

Strains MG1655 W3110 JM109 BW25113 LH1A LH2A LH1C LH2C LH1B LH2B LH1M LH2M LH1H LH2H LH1K LH2K

a Without special instructions, both $\operatorname{ser} A$ and cysE used in this study were feedback-insensitive: $\operatorname{ser} A($ Thr 410 to stop codon) and cysE (Thr 167 Ala) (Liu et al., 2018; Liu et al., 2020).

Table 3 The DCW and L-cysteine production of different metabolically engineered Escherichia coli strains.

\section{Strains}

BW25113-pLH03 LH1A-pLH03 LH2A-pLH03 LH1C-pLH03 LH2C-pLH03 LH1B-pLH03 LH2B-pLH03 LH1M-pLH03 LH2M

a,b,c: Fed-batch fermentation was performed in a $1.5 \mathrm{~L}$ bioreactor.

\section{Hosted file}

image1.emf available at https://authorea.com/users/360132/articles/481845-fitness-ofchassis-cells-and-metabolic-pathways-for-l-cysteine-overproduction-in-escherichia-coli

Figure 1

Figure 2

Hosted file

image2.emf available at https://authorea.com/users/360132/articles/481845-fitness-ofchassis-cells-and-metabolic-pathways-for-l-cysteine-overproduction-in-escherichia-coli

Hosted file 
image3.emf available at https://authorea.com/users/360132/articles/481845-fitness-ofchassis-cells-and-metabolic-pathways-for-l-cysteine-overproduction-in-escherichia-coli

\section{Figure 3}

\section{Hosted file}

image4.emf available at https://authorea.com/users/360132/articles/481845-fitness-ofchassis-cells-and-metabolic-pathways-for-l-cysteine-overproduction-in-escherichia-coli

\section{Hosted file}

image5.emf available at https://authorea.com/users/360132/articles/481845-fitness-ofchassis-cells-and-metabolic-pathways-for-l-cysteine-overproduction-in-escherichia-coli

\section{Hosted file}

image6.emf available at https://authorea.com/users/360132/articles/481845-fitness-ofchassis-cells-and-metabolic-pathways-for-l-cysteine-overproduction-in-escherichia-coli

\section{Hosted file}

image7.emf available at https://authorea.com/users/360132/articles/481845-fitness-ofchassis-cells-and-metabolic-pathways-for-l-cysteine-overproduction-in-escherichia-coli

\section{Figure 4}

\section{Hosted file}

image8.emf available at https://authorea.com/users/360132/articles/481845-fitness-ofchassis-cells-and-metabolic-pathways-for-l-cysteine-overproduction-in-escherichia-coli

\section{Hosted file}

image9.emf available at https://authorea.com/users/360132/articles/481845-fitness-ofchassis-cells-and-metabolic-pathways-for-l-cysteine-overproduction-in-escherichia-coli

\section{Hosted file}

image10.emf available at https://authorea.com/users/360132/articles/481845-fitness-ofchassis-cells-and-metabolic-pathways-for-l-cysteine-overproduction-in-escherichia-coli

\section{Figure 5}

\section{Hosted file}

image11.emf available at https://authorea.com/users/360132/articles/481845-fitness-ofchassis-cells-and-metabolic-pathways-for-l-cysteine-overproduction-in-escherichia-coli

\section{Hosted file}

image12.emf available at https://authorea.com/users/360132/articles/481845-fitness-ofchassis-cells-and-metabolic-pathways-for-l-cysteine-overproduction-in-escherichia-coli

\section{Hosted file}

image13.emf available at https://authorea.com/users/360132/articles/481845-fitness-ofchassis-cells-and-metabolic-pathways-for-l-cysteine-overproduction-in-escherichia-coli

\section{Hosted file}

image14.emf available at https://authorea.com/users/360132/articles/481845-fitness-ofchassis-cells-and-metabolic-pathways-for-l-cysteine-overproduction-in-escherichia-coli 


\section{Hosted file}

image15.emf available at https://authorea.com/users/360132/articles/481845-fitness-ofchassis-cells-and-metabolic-pathways-for-l-cysteine-overproduction-in-escherichia-coli 